\title{
A Measure to Fight China’s Worsening Income Distribution
}

\author{
Hsiung Bingyuan ${ }^{1,2}$ \\ ${ }^{1}$ College of Economics, Zhejiang University, Hangzhou, China \\ ${ }^{2}$ College of Business Administration, China University of Technology, Taipei, Taiwan \\ Email: hsiung@cute.edu.tw
}

Received November $4^{\text {th }}$, 2012; revised December $29^{\text {th }}, 2012$; accepted January $12^{\text {th }}, 2013$

\begin{abstract}
Copyright (c) 2013 Hsiung Bingyuan. This is an open access article distributed under the Creative Commons Attribution License, which permits unrestricted use, distribution, and reproduction in any medium, provided the original work is properly cited.
\end{abstract}

\begin{abstract}
China's income distribution has worsened along with its rapid economic development. It is suggested that the government issues an ID card with a chip and store money in the chip as calculated by a formula based on tax revenues. People can use the money stored for consumption. The measure is likely to prove an effective tool in bringing about a direct and immediate improvement in income distribution.
\end{abstract}

Keywords: Income Distribution; Redistribution Measure

\section{Introduction}

Since the People's Republic of China (PRC) adopted promarket policies in the late 1980s, its economy has expanded with unprecedented speed, resulting in two well documented facts: a near two-digit growth rate which has been sustained for over two decades, and a worsening income distribution. This short article proposes a specific, practical measure to deal with the problem of the widening income gap.

The paper is organized as follows: the problem and policy objectives will be identified in the next section, followed by a specification of the policy measure. Then, an assessment of the measure is made and the measure is compared with other relevant measures. A discussion of the measure from a wider perspective is suggested and then comes the conclusion.

\section{The Problem Identified}

That the PRC has experienced a continuous high growth rate for over two decades has been widely recognized, supported by both vivid stories and hard statistics (Luo Xubei \& Zhu Nong, 2009; Yao, 1999). As a result, many regions and many people have become rich in a short period of time. Not everyone, however, has boarded the train of economic progress. Even in metropolitan areas, stark contrasts between the rich and the poor are not only alarming but sometimes nauseating. The following scenario is common in many a place: in a well lit, cozy McDonalds, youngsters enjoy their breakfast for about 15 RMB (US \$3.00) a person while in the alley just a few feet away, people sit on short stalls, in the open air, and have their traditional Chinese breakfast for 2 RMB (US \$0.40) a person. Moreover, in many rural areas across the country, time seems to have stood still. The rapid economic expansion has not been felt by people in these areas, and it is not uncommon for households to work year round in the field to produce crops that are worth 300 to 500 RMB.

The widening and deteriorating of income distribution clearly has adverse implications. It breeds growing social unrest which endangers society. Various measures have been used to improve income distribution (Musgrave R. \& Musgrave P.,
1989). For instance, offering comprehensive elementary education to the population and providing basic infrastructure such as roads and electricity have been widely adopted in the past. These are effective policies but it takes time for the measures to bear fruit. By contrast, the present paper proposes a policy tool to achieve two goals: First, the measure will benefit individuals (households) directly and immediately; secondly, the tool will at the very least slow down the worsening of the income distribution and more likely improve income distribution, especially closing the gap between the metropolitan and rural areas.

\section{The Tool}

The benchmark case is to issue each person an identity card with a chip (ID card with a chip, IDCC), with the chip capable of storing basic information. Then, a formula is specified by the PRC government to calculate how much money will be put into the card in any given year. The formula will employ tax revenues and census data as inputs. People can use the money stored in the IDCC, say 100 RMB per person, to purchase commodities in grocery stores and supermarkets until the money is depleted. The stores and supermarkets will then apply for reimbursement from a government agency.

Variations of the benchmark version are straightforward. For economically backward regions as well as ethnic minorities, the amount of money stored can be increased. Separately, in addition to the money offered by the central government, provincial and local governments can easily chip in and add money to implement their own policies.

From the fiscal perspective, the IDCC contains elements of different fiscal tools: tax refunds, in-kind transfers, food stamps, and consumption vouchers (Thurow, 1974). From the governance perspective, PRC is like a business entity and the citizens its shareholders. Depending on the profits it makes, the company pays dividends to its shareholders on a regular basis.

\section{An Assessment}

The IDCC has several identifiable benefits. To begin with, 
unlike providing elementary education or building infrastructure that will bear fruits after years or decades, the IDCC will make an impact directly and immediately. In addition, an IDCC is issued to individuals so each and every person, especially those in the rural areas, will share the pie of economic development. Moreover, consumption brought about by the IDCC will have a multiplier effect, accumulating over time and adding to future tax revenues. Consequently, people will actually harvest fruits from seeds they have themselves helped plant.

Furthermore, a mere 100 RMB may be an insignificant amount in the cities, but for people in the rural areas it is a small fortune. People can use it as seed money to raise chickens, ducks, sheep and pigs. The money will make a difference unthinkable in the cities. Finally, consumption enabled by the IDCC and the subsequent economic activities it induces are in a sense bringing about a market economy in the rural areas from a vacuum. This will be an important counterforce to the fast expanding economy in the metropolitan areas. In a nutshell, people, especially those in the rural areas, need to have fish to eat before they can take part in commercial activities and learn how to fish!

Alternatively, while the above beneficial results are tangible and mostly quantifiable, the IDCC will generate intangible and important benefits as well. Specifically, with each individual being issued an IDCC and then enjoying the fruits of economic growth, a weak but perceivable thread is created between the faceless individuals and Big Brother. When their interests are vested in the performance of the whole economy, people will tend to identify with the PRC government and the government will in turn get more feedback and support for its public policies. It is more than evident that the detailed consumption information the IDCC produces will become a valuable data set with respect to which social scientists can do research and based on which the government can form public policies.

The potential difficulties of the IDCC need to be faced too. First, the formula itself will be hard to derive. Conceptually speaking, it is a formula with a certain number divided by a certain number. The numerator could include factors such as the growth rate of the economy, gross national product, tax revenues, etc, and the denominator could be the total population, population over a certain age, or populations of rural areas and/or minorities. Various variables can be used to create a feasible formula, and data for the past ten to twenty years can be used to test the formula and estimate the cost involved. Secondly, implementing the IDCC will involve numerous government agencies, for with the formula and the money determined by the central government, the local governments are to distribute the IDCC to the population and then help deal with the reimbursement process. Cooperation by various government agencies both vertically and horizontally is needed and this will be a challenge to the administrative ability of the PRC.

Third, the people who benefit the most from the IDCC are understandably people living in rural, economically backward and hard to reach regions. There may not be roads or even stores in these places. One possible way to deal with this difficulty is to put the regions into different categories. The IDCC will be issued first not to the most backward regions but perhaps to the second to the worst regions, regions with rudimentary infrastructures and sparse commercial activities. But this also implies that, given that each person has, say, 100 RMB to spend each year, supermarket chains or convenience store chains might find it lucrative to enter these regions and enjoy certain locked-in effects from their entrepreneurial endeavors. Fourth, once the IDCC becomes a fixture in people's lives, it might invite expectations from the public that a certain amount of money will be in the card for them to consume, an expectation that may not be fulfilled if the economy experiences business cycles. One way to deal with this rational expectation is to, as suggested above, group the regions into different categories. When the economy is not doing well or the tax revenues are below par, only people in certain categories will have money stored in their IDCC. This actually implies that the IDCC functions as an automatic stabilizer for business cycles. When the economy is in a trough the rural and less developed regions will get economic resources and this will help close the gap between the metropolitan and rural areas.

Whether the IDCC should have a sunset clause is open to discussion. As the income distribution improves to reach a certain level, issuing the IDCC to the whole population may not be necessary. The measure, however, can become a more refined tool to deal with problems of a more limited scope. For instance, people from the economically deprived regions or ethnic minorities could use their personalized IDCC to pay tuition or pay off student loans in pursuing their education.

\section{Relevant Considerations}

The IDCC measure can be compared with other relevant fiscal tools, illustrating their strengths as well as weaknesses. Bangladeshi economist Muhammad Yunus launched a small loan (microcredit) scheme in the rural areas of India to great success, earning him the Nobel Peace Prize in 2006. The IDCC and the small loan approach are common in that even with a small amount of money initially, both measures will generate a chain reaction, producing changes both quantitatively and qualitatively. The difference between the two is that while the small loan measure is conducted with selective points (individuals), the IDCC measure is spread over the whole area (the whole population), so to speak.

Alternatively, the contrast between the IDCC measure and the consumption voucher is also illuminating. While the consumption voucher is normally issued as a one-shot measure, aiming to provide a stimulus to the economy, the IDCC infusion is repeated yearly, providing not only continuous streams of stimuli but more importantly the resources needed to fight the worsening income distribution. That is, the IDCC will help improve both efficiency and equity. In addition, food stamps in the US have been replaced by Electronic Benefit Transfer cards $(\mathrm{EBT})$. The main differences between the EBT and the IDCC are that the later is not meant to maintain a basic level of living per se and that a major goal of the IDCC is to expand the reach of the market economy.

Moreover, the IDCC measure is not only applicable to the PRC, it is likely to prove effective in other countries and areas such as India, Pakistan and Africa, in closing the gap between the developed and the less developed regions. In addition, foreign aids can actually be made with the proviso of IDCC use, e.g., in providing aid to North Korea, the UN could demand the IDCC measure be implemented, ensuring that the people will get the aid directly.

\section{Conclusion}

The problems of widening income distribution and the 
worsening urban-rural gap have a long history in various societies, and different measures have been employed to deal with them. At the beginning of the 21st century, the PRC is facing similar problems, but on a scale that is arguably more serious by an order of magnitude. If social unrest bursts out in the PRC, then conceivably it will have adverse impacts to both the PRC's neighbors and other regions through the repercussion on economic activity.

Technological advances such as electronic chips, mass information processing, and wireless communication, however, have enabled modern societies to fight the old problems with new tools. The IDCC measure, dealing with old problems in an old civilization, is a new tool and is likely to yield encouraging results, thus turning a new page in the history of public finance!

\section{Acknowledgements}

I thank Hsienguo Yao, Jingchuan Shi, Chiendong Win, Kelly
Olds, and Weidong Zhang for helpful comments. Also, I am grateful to the Center of Law and Public Policies, National Taiwan University, for research support and Tzehan Kao as well as Meya Tseng for research assistance.

\section{REFERENCES}

Luo, X. B., \& Zhu, N. (2009). Rising income inequality in China: A race to the top. World Bank Policy Working Paper, No. 4700.

Musgrave, R., \& Musgrave, P., (1989). Public finance in theory and practice (5th ed.). New York: McGraw-Hill Book Co.

Thurow, L. C. (1974). Cash versus in-kind transfers. American Economic Review Papers and Proceedings, 64, 190-195.

Yao, D. (1999). Urban-biased policies and rising income inequality in China. American Economic Review Papers and Proceedings, 89, 306-310. doi:10.1257/aer.89.2.306 